\section{Differences in chemical, physical and microbiological characteristics of Italian burrata cheeses made in artisanal and industrial plants of Apulia Region}

\author{
Stefano Rea, ${ }^{1}$ Leonardo Marino, ${ }^{2}$ \\ Roberta Stocchi, ${ }^{1}$ Raffaella Branciari, ${ }^{3}$ \\ Anna Rita Loschi, ${ }^{1}$ Dino Miraglia, ${ }^{3}$ \\ David Ranucci ${ }^{3}$ \\ School of Biosciences and Veterinary \\ Medicine, University of Camerino, \\ Matelica (MC); ${ }^{2}$ Veterinary Practitioner, \\ Foggia; ${ }^{3}$ Department of Veterinary \\ Medicine, University of Perugia, Perugia, \\ Italy
}

\section{Abstract}

The burrata cheese is a traditional product from Southern Italy, consisting of an envelope of pasta filata (stretched curd) filled with cream and pasta filata strips (usually leftovers from mozzarella production). Physical [water activity $\left(\mathrm{a}_{\mathrm{w}}\right), \mathrm{pH}$ ], chemical (moisture, $\mathrm{NaCl}$ content) and microbiological [total viable count (TVC), Listeria monocytogenes, Salmonella spp., Yersinia enterocolitica, Bacillus cereus, Escherichia coli, Enterobacteriaceae, coagulase-positive staphylococci] characteristics of burrata cheeses manufactured in artisanal and industrial plants were evaluated. The artisanal burrata showed lower $a_{w}$ values in the filling and the final product. The same was recorded in the filling for the moisture, probably due to differences between the types of cream used in the artisanal and the industrial cheesemaking. The $\mathrm{pH}$ value of the filling differed between the two groups but no difference was recorded in the final product. Microbiological differences were also recorded, with higher values for TVC and $E$. coli in artisanal than industrial burrata All samples were negative for the other microbial determinations, with the exception of coagulase-positive staphylococci and $Y$. enterocolitica, which were detected in artisanal burrata. Differences in cheesemaking process were probably responsible for the strong variability of the physical and chemical data between the two cheeses; furthermore, differences in the hygienic features were also recorded. Even though artisanal products showed lower $\mathrm{a}_{\mathrm{w}}$ and $\mathrm{pH}$ values and higher $\mathrm{NaCl}$ concentration, the higher $E$. coli loads highlighted the need for a more accurate compliance with hygienic procedures along the artisanal cheesemaking process.

\section{Introduction}

Burrata is a traditional cheese produced in the Apulia Region (Southern Italy), particularly in Bari, Barletta-Andria-Trani and Foggia Provinces, as well as in Martina Franca, a town in the Province of Taranto. The product is a pasta filata (stretched curd) cheese consisting of a filling made of cream mixed with mozzarella cheese strips (usually leftovers from mozzarella production) inside an envelope made of mozzarella. This product came probably from the idea of reusing the scrap from mozzarella cheese production, and mixing it with cream to be used as filling of a cheese envelope shaped like a caciocavallo cheese (Salvadori del Prato, 2001). Although burrata cheese is not included in the list of EU protected agricultural products, it is listed in the register of traditional foodstuffs of the Apulia Region and is known worldwide (Lo Russo, 2008). Its production technology is far from being standardised, having not yet achieved a legal protection. This allows manufacturers to use production techniques that are sometimes very different. Moreover, different raw materials can be used depending on the manufacturer [i.e. whey cream obtained by spontaneous rising or ultra high temperature (UHT) centrifuged cream for the stuffing]. These could result in products different in shape, sensory traits, or safety aspects.

The absence of product and production standards in burrata cheesemaking and consequently the presence of different products on the market (Tantillo, 2007) can also influence the duration of their shelf life. For these reasons data on microbial, physical and chemical characteristics of burrata cheese are necessary for dairy producers to achieve a sort of standardisation that may contribute to improve the quality and safety of such a product.

The aim of the present study was to evaluate the physical, chemical and hygienic characteristics of burrata cheese manufactured in two dairy plants that used different raw materials and production techniques.

\section{Materials and Methods}

\section{Cheesemaking process and sample collection}

Samples of milk, intermediate products (cream, pasta filata strips, and envelope) throughout the cheesemaking process, and final products (burrata cheeses) were collected in two different sessions from an artisanal (AP) and an industrial (IP) dairy plant, both located in the Foggia Province (Apulia Region, Southern Italy). The burrata cheeses were produced according to two different production
Correspondence: Stefano Rea, School of Biosciences and Veterinary Medicine, University of Camerino, via Circonvallazione 93/95, 62024 Matelica (MC), Italy.

Tel: +39.320 .4381189 - Fax: +39.0737 .403402$

E-mail: stefano.rea@unicam.it

Key words: Cheesemaking; Burrata cheese; Food quality; Food hygiene; Food safety.

Contributions: the authors contributed equally.

Conflict of interest: the authors declare no potential conflict of interest.

Received for publication: 10 March 2016.

Revision received: 27 April 2016.

Accepted for publication: 27 April 2016.

This work is licensed under a Creative Commons Attribution-NonCommercial 4.0 International License (CC BY-NC 4.0).

(C) Copyright S. Rea et al., 2016

Licensee PAGEPress, Italy

Italian Journal of Food Safety 2016; 5:5879

doi:10.4081/ijfs.2016.5879

techniques. According to the tradition, the artisanal process was entirely carried out manually starting from raw milk and whey cream obtained by spontaneous rising from the water used for the curd stretching, collected from the previous production cycles. The industrial cheesemaking used pasteurised milk and UHT cream obtained by centrifugation and all the steps were performed using specific equipment, typical of most mozzarella production lines. Briefly, for both productions, the milk was added with natural whey starter $(3 / 100 \mathrm{~L})$ and, after a partial acidification ( $\mathrm{pH} 6.1$ ), heated to $37^{\circ} \mathrm{C}$. Then, calf rennet was added (15-30 $\mathrm{mL} / 100 \mathrm{~L}$ ) and the coagulation took place after $30 \mathrm{~min}$. The curd was cut and kept under whey for maturation (acidification) for $30 \mathrm{~min}$. Later the curd was kneaded under hot salted water $\left(85-90^{\circ} \mathrm{C}\right)$ and stretched to produce pasta filata strips and envelope. The cream was added to the strips to assemble the filling. Finally, it was used to fill the mozzarella envelope that was closed thereafter.

Two sampling sessions were performed in each plant. In each sampling session from the same batch, 5 samples were collected at the IP and 5 samples at the AP: the raw material (milk), the semi-finished (cream, pasta filata used for the filling and the envelope, and whole filling made with cheese strips and cream), and the finished product (burrata ready for consumption). The collection was performed under sterile conditions: samples were packaged in sterile plastic bags, refrigerated and sent to the laboratory of the School of Biosciences and Veterinary Medicine, 
University of Camerino [Matelica (MC), Italy].

\section{Analytical determination}

For the physical and chemical traits, activity water $\left[\mathrm{a}_{\mathrm{w}}\right.$; using a BTRS1 Rotronic hygroscope (PBI International, Milan, Italy)], pH [according to Bendall (1975) measured using a Beckman 310 pHmeter (Beckman, Galway, Ireland)], moisture, and $\mathrm{NaCl}$ content (AOAC, 1990) were determined. Determinations were performed on all the samples in duplicate. Milk samples were analysed only for $\mathrm{pH}$ and protein content (AOAC, 1990).

As for the microbiological evaluation, total viable count (TVC), different foodborne pathogens (Listeria monocytogenes, Salmonella spp., Yersinia enterocolitica, Bacillus cereus) and process hygiene criteria (Escherichia coli, coagulase-positive staphylococci) were considered. These analyses were performed on all samples in duplicate except for the filling, whose overall microbiological characteristics were obtained from the analysis of the cream and the pasta filata strips used for its preparation.

The quantitative determination of microbiological parameters was carried out by inoculating the media with specific scalar dilutions of $10 \mathrm{~g}$ (or mL) of sample homogenised in $90 \mathrm{~mL}$ of saline solution with peptone, while for the qualitative evidence, $25 \mathrm{~g}$ (or $\mathrm{mL}$ ) of the sample were diluted 1:10 in specific enrichment broths, properly incubated and then inoculated on specific media. The following determinations were performed.

TVC on Plate Count Agar (PCA) (Biolife, Milan, Italy) and only milk samples on Plate Count Agar Wide Skim Milk (Biolife), in both cases incubated at $30^{\circ} \mathrm{C}$ for 72 h. E. coli on selective $E$. coli/Coliform Medium (Oxoid, Basingstoke, UK), incubated at $37^{\circ} \mathrm{C}$ for $24 \mathrm{~h}$, and subsequently in TBX Medium (Oxoid) at $44^{\circ} \mathrm{C}$ for $18-24 \mathrm{~h}$ for confirmation. Coagulasepositive staphylococci on Baird Parker Medium (Biolife), incubated at $37^{\circ} \mathrm{C}$ for $24-48 \mathrm{~h}$, followed by confirmation of the typical colonies using Staphylase test (Oxoid). B. cereus on $B$. cereus Agar Base (PEMBA) (Biolife), added with $B$. cereus Antimicrobic Supplement (Biolife), incubated at $30^{\circ} \mathrm{C}$ for $24-48 \mathrm{~h}$, and subsequently on Blood Agar at $30^{\circ} \mathrm{C}$ for additional 24 h. Salmonella spp. with a pre-enrichment in Buffered Peptone Water (Oxoid), followed by selective enrichment on Rappaport Vassiliadis Soya Peptone (RVS) Broth (Oxoid) at $42^{\circ} \mathrm{C}$ for $24 \mathrm{~h}$, and then on Chromogenic Salmonella Agar Base (Biolife) and Brilliant Green Agar (Biolife), at $37^{\circ} \mathrm{C}$ for $24 \mathrm{~h}$. The identification was performed using the API $20 \mathrm{E}$ biochemical test (bioMérieux, Italy), as specified in the manufacturer's guide. $L$. monocytogenes on Listeria Enrichment Broth Low Acriflavine (LEBB) (Biolife) incubated at $30^{\circ} \mathrm{C}$ for $48 \mathrm{~h}$, and subsequently on Listeria Oxford Agar Base (Biolife) and ALOA Agar Ottaviani Agosti (Biolife) at $37^{\circ} \mathrm{C}$ for $24-48 \mathrm{~h}$. The identification was made through the biochemical test API Listeria (bioMérieux, Marcy l'Etoile, France), as specified in the manufacturer's guide. $Y$. enterocolitica on selective enrichment medium Yersinia PSB Broth (Biolife) incubated at $25^{\circ} \mathrm{C}$ for 5 days, and subsequently on Yersinia Selective Agar Base (Oxoid), supplemented with Yersinia Selective Supplement (Oxoid) incubated at $25^{\circ} \mathrm{C}$ for 24 $48 \mathrm{~h}$, after treatment in a solution of $\mathrm{KOH}$ $0.5 \%$. The suspect colonies were identified using the API $20 \mathrm{E}$ biochemical test (bioMérieux), according to the manufacturer's guide, except for the incubation temperature, which was $30^{\circ} \mathrm{C}$ instead of $37^{\circ} \mathrm{C}$.

All quantitative microbiological data were reported as colony forming unit (CFU)/g or $\mathrm{mL}$ and converted to $\log _{10}$.

\section{Statistical analyses}

Data derived from the different sampling

Table 1. Physical and chemical data of samples collected during the artisanal and industrial production of burrata cheese ( $\mathrm{n}=10$ ).

\begin{tabular}{|c|c|c|c|c|}
\hline Sample & Parameter & AP & IP & P* \\
\hline Cream & $\begin{array}{l}\mathrm{a}_{\mathrm{w}} \\
\mathrm{pH} \\
\text { Moisture (\%) } \\
\mathrm{NaCl}(\%)\end{array}$ & $\begin{array}{c}0.953 \pm 0.014 \\
4.96 \pm 0.43 \\
43.63 \pm 0.28 \\
1.84 \pm 0.67\end{array}$ & $\begin{array}{c}0.964 \pm 0.007 \\
7.22 \pm 0.02 \\
61.89 \pm 1.49 \\
0.22 \pm 0.11\end{array}$ & $\begin{array}{l}0.267 \\
<0.001 \\
<0.001 \\
0.003\end{array}$ \\
\hline Mozzarella strips & $\begin{array}{l}\mathrm{a}_{\mathrm{w}} \\
\mathrm{pH} \\
\text { Moisture (\%) } \\
\mathrm{NaCl}(\%)\end{array}$ & $\begin{array}{c}0.961 \pm 0.002 \\
6.16 \pm 0.07 \\
70.72 \pm 0.70 \\
0.41 \pm 0.11\end{array}$ & $\begin{array}{c}0.963 \pm 0.003 \\
6.68 \pm 0.12 \\
69.96 \pm 1.16 \\
0.80 \pm 0.33\end{array}$ & $\begin{array}{c}0.459 \\
<0.001 \\
0.304 \\
0.069\end{array}$ \\
\hline Filling & $\begin{array}{l}\mathrm{a}_{\mathrm{w}} \\
\mathrm{pH} \\
\text { Moisture (\%) } \\
\mathrm{NaCl}(\%)\end{array}$ & $\begin{array}{c}0.957 \pm 0.005 \\
6.21 \pm 0.10 \\
52.41 \pm 1.85 \\
1.07 \pm 0.44\end{array}$ & $\begin{array}{c}0.967 \pm 0.001 \\
6.73 \pm 0.11 \\
65.82 \pm 0.74 \\
0.22 \pm 0.11\end{array}$ & $\begin{array}{l}0.016 \\
<0.001 \\
<0.001 \\
0.009\end{array}$ \\
\hline Burrata cheese & $\begin{array}{l}\mathrm{a}_{\mathrm{w}} \\
\mathrm{pH} \\
\text { Moisture (\%) } \\
\mathrm{NaCl}(\%)\end{array}$ & $\begin{array}{c}0.963 \pm 0.003 \\
6.35 \pm 0.14 \\
59.46 \pm 2.62 \\
0.99 \pm 0.56\end{array}$ & $\begin{array}{c}0.969 \pm 0.001 \\
6.51 \pm 0.15 \\
62.59 \pm 0.67 \\
0.12 \pm 0.01\end{array}$ & $\begin{array}{l}0.010 \\
0.189 \\
0.060 \\
0.020\end{array}$ \\
\hline
\end{tabular}

AP, artisanal production; IP, industrial production; $\mathrm{a}_{w}$, water activity. Values are expressed as mean \pm standard deviation. * ${ }^{*}$ Significant for $\mathrm{P}<0.05$.

Table 2. Microbiological data $\left(\log _{10}\right.$ colony forming unit/g or $\left.\mathrm{mL}\right)$ of samples collected during the artisanal and industrial production of burrata cheese $(\mathbf{n}=10)$.

\begin{tabular}{|c|c|c|c|c|}
\hline Sample & Parameter & AP & IP & P* \\
\hline Cream & $\begin{array}{l}\text { TVC } \\
\text { E. coli }\end{array}$ & $\begin{array}{l}8.35 \pm 0.11 \\
4.51 \pm 0.33\end{array}$ & $\begin{array}{l}2.09 \pm 0.93 \\
1.13 \pm 0.25\end{array}$ & $\begin{array}{l}<0.001 \\
<0.001\end{array}$ \\
\hline Mozzarella strips & $\begin{array}{l}\text { TVC } \\
\text { E. coli }\end{array}$ & $\begin{array}{l}6.93 \pm 0.04 \\
5.30 \pm 0.07\end{array}$ & $\begin{array}{l}5.51 \pm 0.53 \\
1.85 \pm 0.40\end{array}$ & $\begin{array}{c}0.006 \\
<0.001\end{array}$ \\
\hline Burrata cheese & $\begin{array}{l}\text { TVC } \\
\text { E. coli }\end{array}$ & $\begin{array}{l}7.85 \pm 0.28 \\
5.35 \pm 0.11\end{array}$ & $\begin{array}{l}7.11 \pm 0.17 \\
3.62 \pm 0.24\end{array}$ & $\begin{array}{c}0.017 \\
<0.001\end{array}$ \\
\hline
\end{tabular}

AP, artisanal production; IP, industrial production; TVC, total viable count; E. coli, Escherichia coli. Values are expressed as mean \pm standard deviation. *Significant for $\mathrm{P}<0.05$. 
sessions were aggregated for statistical analyses. The physical, chemical and microbiological data obtained in all the different samples were analysed with an unpaired $T$ test (Statview SAS, Cary, NC, USA) to detect differences between products from AP and IP. The significance level was set at $\mathrm{P}<0.05$.

\section{Results}

As for the milk, no significant difference $(\mathrm{P}=0.872)$ was recorded for $\mathrm{pH}$ values between AP $(6.75 \pm 0.06)$ and IP $(6.70 \pm 0.01)$; protein content differed significantly $(\mathrm{P}=0.002)$ between AP $(3.00 \pm 0.06)$ and IP $(3.36 \pm 0.06)$ (data not shown).

As for the semifinished and finished products, the physical and chemical characteristics are reported in Table 1 and the microbiological data are shown in Table 2.

Differences in $\mathrm{pH}$ values were recorded in all the semi-finished samples, with a constantly lower value in AP than in IP, but not in the final products. Differences in the cream used, and therefore in the filling, were recorded also for moisture content (higher in industrial than in artisanal cream) and for $\mathrm{NaCl}$ concentration (lower in industrial than in artisanal cream).

The microbiological counts revealed higher values of TVC and $E$. coli in cream, mozzarella strips and final products from AP than those from IP. Coagulase-positive staphylococci were detected in all the artisanal samples collected but the counts were always well below the limit set by the European Commission Regulation $\mathrm{n}$. 1441/2007 (European Commission, 2007). No coagulase-positive staphylococci were detected in IP samples. No Salmonella spp., B. cereus and $L$. monocytogenes were detected in both $\mathrm{AP}$ and IP samples. $Y$. enterocolitica was qualitatively detected in samples obtained in the second sampling session from AP mozzarella strips and burrata cheese and from IP pasteurised milk (data not shown).

\section{Discussion}

The different cheesemaking technologies, mainly consisting in the cream used but also in the pasta filata envelope and strips, could be responsible for the chemical and physical differences recorded between AP and IP samples. The values of $\mathrm{NaCl}$ detected in the cream are quite interesting: the significantly $(\mathrm{P}=0.003)$ higher value in AP samples is strictly related to the traditional cheesemaking technology that provides for the addition of hot water with $10 \%$ $\mathrm{NaCl}$ used for curd stretching, from which the artisanal cream is recovered by spontaneous raising, as previously described in the cheesemaking process. The spontaneous rising can even explain the much lower $(\mathrm{P}<0.001) \mathrm{pH}$ observed in the artisanal cream. Moreover, the proportion of the cream and mozzarella strips used for preparing the filling (generally not standardised in the artisanal cheesemaking) could have affected the final products that differed only for $a_{w}$ and $\mathrm{NaCl}$ values. The $a_{w}$ parameter is relevant for microbial growth and the values recorded in both types of burrata cheese were high enough to allow almost all pathogenic microorganisms to grow if other hurdles are not provided in the production process. Furthermore, in these fresh cheeses the salt content has to be low for improving the taste perception by the consumer. The effect of salt in prolonging the shelf life of mozzarella cheese is almost contradictory, as longer durations were obtained for mozzarella without or with low $(0.23 / 100 \mathrm{~g})$ salt concentration (Faccia et al., 2012).

From a microbiological perspective the AP samples showed higher TVC and $E$. coli values than IP. Moreover, coagulase-positive staphylococci and $Y$. enterocolitica were found in samples from AP, even though at low concentration or as not pathogenic strains, respectively (data not reported). The TVC, considered as a process hygiene parameter in some foods, could be strongly affected by the number of Lactobacillus and Lactococcus (LAB) in cheeses, where they play an important role as hurdle against microbial growth. Higher TVC values were constantly recorded in all products from $\mathrm{AP}$, which showed lower $\mathrm{pH}$ values in the intermediate samples (cream, pasta filata strips and filling). The production procedure of whey cream obtained by spontaneous rising (24 $\mathrm{h}$ at room temperature) used in the AP can explain the growth of a much higher number of $\mathrm{LAB}$, as well as other bacteria, in products from AP than those from IP. As emphasised by other authors (de Candia et al., 2007), the LAB present in the whey used as starter for making pasta filata (strips and envelope) may also have influenced the characteristics of the products. Nonetheless, much higher values of $E$. coli were recorded in cream, mozzarella strips and final products from AP than those from IP. This parameter highlights deficiencies especially in the hygiene process. The whey cream obtained by spontaneous rising and the whey used as starter may be responsible for the high amount of $E$. coli in the products, and even the high temperature $\left(85-90^{\circ} \mathrm{C}\right)$ used in the kneading/stretching step of pasta filata production is not sufficient to reduce the $E$. coli load to an acceptable level. Indeed, Spano et al. (2003) reported that the stretching of curd at temperatures over $80^{\circ} \mathrm{C}$ should be able to eliminate up to $5 \log$ of $E$. coli $0157: \mathrm{H} 7$, but time/temperature curve has to be carefully taken into consideration to obtain effective results (Trevisani et al., 2014). Also, in IP the trend of $E$. coli. increase in the final product was observed, with average values higher than the legal limit of acceptance set by the European Commission Regulation $n$. 1441/2007 (European Commission, 2007). This suggests that $E$. coli contamination and/or growth during the last phases of the cheesemaking could occur, i.e. during filling/closing, immersion for hardening, and packaging steps. The reported data disagree with Dambrosio et al. (2013), who did not observe burrata samples exceeding the limit of $E$. coli set by the EC Regulation, while $3.7 \%$ of samples were positive for coagulase-positive staphylococci with values greater than $3 \log$ $\mathrm{CFU} / \mathrm{g}$. No relevant pathogens were recorded in products from AP and IP, and the level of coagulase-positive staphylococci was almost low, in contrast with other studies on mozzarella cheese, where high levels of such bacteria were reported (De Luca et al., 1997). The presence of virulent $Y$. enterocolitica is reported in different cheeses (Hanifian and Khani, 2012; Kowalich and Lobacz, 2015) but no data on mozzarella or burrata cheese is available from the literature. The milk is reported as the major source of such a contamination (EFSA, 2013) and even pasteurised milk was found to be positive to $Y$. enterocolitica (Gupta et al., 2015). Even if not detected in pathogenic form, the necessity of improving the control on this microorganism should be emphasised.

\section{Conclusions}

The differences observed in burrata cheesemaking have to be taken into consideration when a proper risk analysis is performed. The bacterial contamination of the product could be reduced only if an appropriate temperature/time ratio, ensured by the curd kneading at $85-90^{\circ} \mathrm{C}$ during the stretching step, is reached. Control strategies to avoid $E$. coli proliferation are further needed, especially in the artisanal process and in particular during the preparation of whey cream obtained by spontaneous rising and used in the filling. 


\section{References}

AOAC, 1990. Official methods of analysis. 15th ed. Association of Official Analytical Chemists, Washington, DC, USA.

Bendall JR, 1975. Cold contracture and ATP turnover in the red and white musculature of the pig, post-mortem. J Sci Food Agr 26:5571.

Dambrosio A, Quaglia NC, Saracino M, Malcagni M, Montagna C, Quinto M, Lorusso V, Normanno G, 2013. Microbiological quality of Burrata cheese produced in Puglia Region: Southern Italy. J Food Protect 11:1824-993.

de Candia S, De Angelis M, Dunlea E, Minervini F, McSweeney PLH, Faccia M, Gobetti M, 2007. Molecular identification and typing of natural whey starter cultures and microbiological and compositional properties of related traditional mozzarella cheeses. Int J Food Microbiol 119:181-91.

De Luca G, Zanetti F, Stampi S, 1997.
Staphylococcus aureus in dairy products in the Bologna area. Int $J$ Food Microbiol $35: 267-70$.

EFSA, 2013. The European Union summary report on trends and sources of zoonoses, zoonotic agents and food-borne outbreaks in 2013. EFSA J 13:3991.

European Commission, 2007. European Commission regulation of 5 December 2007 amending Regulation (EC) N. 2073/2005 on microbiological criteria for foodstuffs, 1441/2007/EC. In: Official Journal, L 322, 07/12/2007, pp. 12-29.

Faccia M, Mastromatteo M, Conte A, Del Nobile MA, 2012. Influence of the different sodium chloride concentrations on microbiological and physico-chemical characteristics of mozzarella cheese. J Dairy Res 79:390-6.

Gupta V, Gulati P, Bhagat N, Dhar MS, Virdi JS, 2015. Detection of Yersinia enterocolitica in food: an overview. Eur J Clin Microbiol Infect Dis 34:641-50.

Hanifian S, Khani S, 2012. Prevalence of viru- lent Yersinia enterocolitica in bulk raw milk and retail cheese in northern-west of Iran. Int J Food Microbiol 155:89-92.

Kowalick J, Lobacz A, 2015. Development of a predictive model describing the growth of Yersinia enterocolitica in Camembert-type cheese. Int J Food Sci Technol 50:811-8.

Lo Russo G, 2008. Burrata cuore di panna e mozzarella. Origine 4:32-6.

Salvadori del Prato 0,2001. Trattato di tecnologia casearia. Calderini Edagricole ed., Bologna, Italy.

Spano G, Goffredo E, Beneduce L, Tarantino D, Dupuy A, Massa S, 2003. Fate of Escherichia coli 0157: H7 during the manufacture of mozzarella cheese. Lett Appl Microbiol 36:73-6.

Tantillo MG, 2007. I prodotti tradizionali pugliesi: burrata. Infosei, Bari, Italy.

Trevisani M, Mancusi R, Valero A, 2014. Thermal inactivation kinetics of Shiga toxin-producing Escherichia coli in buffalo mozzarella curd. J Dairy Sci 97:642-50. 